\title{
The Research on Influencing Factors of Financial Services of Chinese Logistics Enterprises
}

\author{
ZHANG Xiaoli ${ }^{1}$, AN Tongxin ${ }^{2}$ * \\ ${ }^{1}$ School of Business, University of Jinan, Jinan 250002, China; \\ ${ }^{2}$ School of Business, University of Jinan, Jinan 250002, China. \\ * Corresponding author
}

Keywords: logistics enterprises; logistics finance; factor analysis.

Abstract. Logistics finance plays an important role in the development of logistics enterprises, and there are many factors influencing the development of logistics finance. In order to improve the level of financial services carried out by China's logistics enterprises, the original data of factors affecting logistics financial development were obtained by issuing questionnaires from the perspective of logistics enterprises, and analyzed it with factor analysis. Four significant common factors influencing financial services of logistics enterprises were determined as follows: the pledge factors, logistics enterprise internal factors, assets and credit factors and the external environment factors. Based on the four elements and the actual of China's logistics enterprises in developing financial services, this paper puts forward corresponding measures and suggestions for improving logistics financial services.

\section{Introduction}

With the development of China's economy, the market demand of financial services provided by the combination of logistics and finance is increasing, at this time, logistics finance comes into being. Prof ZOU Xiao-peng and prof TANG Yuan-qi of the school of economics of zhejiang university have formally proposed the concept of "logistics finance" for the first time in China ${ }^{[1]}$. The development of logistics finance is of great significance to the whole supply chain including logistics enterprises, financing enterprises and Banks ${ }^{[2]}$. $\mathrm{Li}$ Yi-xue has identified logistics financial risks and constructed a risk identification framework ${ }^{[3]}$. Logistics enterprises should pay attention to the following aspects when developing financial services: credit creation and maintenance among the three major players of logistics finance, risk of logistics financial services, and efficiency of logistics financial services ${ }^{[4]}$. Based on the perspective of commercial Banks, WANG Yan identified and measured the risk of logistics finance ${ }^{[5]}$. He Ming-ke and Qian Wen-bin systematically studied the risk management of logistics finance ${ }^{[6]}$.

Logistics enterprises, as a bridge in the operation of logistics finance, connect customers and financial institutions, whose important status and role is self-evident. However, there is little literature on logistics finance from the perspective of logistics enterprises. Based on this, this paper adopts factor analysis method to sort out the influencing factors of logistics enterprises' financial services development and puts forward corresponding measures and Suggestions.

\section{Questionnaire Design and Data Collection}

\subsection{Questionnaire design.}

Firstly, according to the literature research and the guidance of experts in the field of logistics and logistics enterprise mentors, this paper determines 12 influencing factors. At the same time, this study used a seven-level scale to score each factor, and the score value increased from 1 to 7 in order of importance, representing the importance of developing financial services for logistics enterprises from very unimportant to very important.

\subsection{Data collection.}

In this study, data were collected by sending electronic questionnaires and paper questionnaires, and 93 valid questionnaires were collected in total, excluding incomplete answers and invalid questionnaires with the same option. Among them, 26 effective questionnaires were collected from experts in the field of 
logistics, accounting for 27.96\%; Collected 43 valid questionnaires from logistics enterprise employees, accounting for 46.24\%; A total of 24 valid questionnaires were collected from postgraduates and doctoral students with relevant internship experience, accounting for $25.80 \%$.

\section{Analysis of Influencing Factors of Logistics Financial Services}

On the premise of keeping data information to the maximum extent, factor analysis can be used to explain the relationship between complex variables with relatively few factors, which plays an important role in the simplification of logistics finance development research.

\subsection{The applicability test of factor analysis.}

Before the analysis, the applicability of the data should be tested to confirm whether the data meets the conditions for factor analysis. The tool selected in this study was SPSS24.0 software and relevant tests were conducted. The results are shown in table 2. The value of KMO in this paper is 0.639 greater than 0.5 , which can be further analyzed.

\subsection{Determination of common factors.}

Table 2 KMO and Bartlett's Test

\begin{tabular}{lll}
\hline KMO Measure of Sampling Adequacy. & 0.639 \\
\hline Bartlett's Test Approx. Chi-Square & 319.417 \\
of Sphericity & df & 66 \\
& Sig. & 0.000 \\
\hline
\end{tabular}

In this study, the principal component analysis method was used to extract the common factors and select the feature root with the characteristic value greater than 1, and finally four common factors were extracted. The four common factors are set to $F_{1}, F_{2}, F_{3}$ and $F_{4}$ according to the contribution rate from large too small. When four common factors are extracted in this paper, the cumulative variance contribution rate is $66.907 \%$. That is to say, the four common factors extracted in this paper can explain $66.907 \%$ of the original variable information, which can be further analyzed (see table 3 ).

Table 3 Total variance interpretation

\begin{tabular}{|c|c|c|c|c|c|c|c|c|c|}
\hline \multirow[b]{2}{*}{ Component } & \multicolumn{9}{|c|}{ Extraction Sums of Squared } \\
\hline & Total & $\begin{array}{c}\% \text { of } \\
\text { variance }\end{array}$ & Cumulative\% & Total & $\begin{array}{c}\% \text { of } \\
\text { variance }\end{array}$ & Cumulative \% & Total & $\begin{array}{c}\% \text { of } \\
\text { variance }\end{array}$ & Cumulative \% \\
\hline 1 & 2.763 & 23.028 & 23.028 & 2.763 & 23.028 & 23.028 & 2.412 & 20.097 & 20.097 \\
\hline 2 & 2.129 & 17.739 & 40.767 & 2.129 & 17.739 & 40.767 & 1.963 & 16.356 & 36.453 \\
\hline 3 & 1.725 & 14.373 & 55.140 & 1.725 & 14.373 & 55.140 & 1.882 & 15.681 & 52.134 \\
\hline 4 & 1.412 & 11.767 & 66.907 & 1.412 & 11.767 & 66.907 & 1.773 & 14.773 & 66.907 \\
\hline 5 & 0.885 & 7.377 & 74.284 & & & & & & \\
\hline 6 & 0.760 & 6.336 & 80.620 & & & & & & \\
\hline 7 & 0.588 & 4.898 & 85.518 & & & & & & \\
\hline 8 & 0.467 & 3.893 & 89.411 & & & & & & \\
\hline 9 & 0.388 & 3.231 & 92.642 & & & & & & \\
\hline 10 & 0.336 & 2.801 & 95.442 & & & & & & \\
\hline 11 & 0.296 & 2.467 & 97.910 & & & & & & \\
\hline 12 & 0.251 & 2.090 & 100.000 & & & & & & \\
\hline
\end{tabular}

\subsection{Naming and analysis of common factors.}

After 5 iterations, the loading matrix is converged (see table 4), and the common factor is named according to the rotated matrix. 
$\mathrm{F}_{1}$ has the highest score on the three influencing factors of $\mathrm{X}_{3}, \mathrm{X}_{4}$ and $\mathrm{X}_{5}$. These three factors reflect the pledge, so $\mathrm{F}_{1}$ is named as the pledge factors. First of all, the value of the pledge directly determines the repayment ability of the loan enterprise. Therefore, the accurate value assessment of the pledge and the rapid realization ability of the pledge can largely reduce the risk coefficient of the logistics enterprise. Secondly, as the pledges in the logistics finance business are mostly stored in the warehouses of logistics enterprises, the supervision of the pledge during this period cannot be ignored.

$F_{2}$ has the highest score in four influencing factors of $X_{6}, X_{7}, X_{8}$ and $X_{9}$. These four factors reflect the internal conditions of logistics enterprises, so $F_{2}$ is named as logistics enterprise internal factors. For an enterprise to operate efficiently and effectively, it must have professional talents, advanced equipment, technology and perfect system. The operation of logistics finance should be based on advanced equipment and technology, and relevant personnel should perform their duties and play the guiding role of professionals. Meanwhile, the entire process should be supervised by a sound and perfect system to ensure the reliability of operation.

$F_{3}$ has the highest score in the three factors of $X_{10}, X_{11}$ and $X_{12}$. The first two factors are assets and credit status of the financing enterprise and the bank's willingness to cooperate also depends on assets and credit status of the cooperative enterprise to some extent. So $F_{3}$ is named as assets and credit factors. Assets and credit factors is the part that logistics enterprises cannot grasp the external uncertainty. Once the financing enterprise defaults, the risk will be transferred to the logistics enterprise.

$\mathrm{F}_{4}$ has the highest score on the two factors of $\mathrm{X}_{1}$ and $\mathrm{X}_{2}$. These two factors describe the external environment faced by logistics enterprises. So $\mathrm{F}_{4}$ is named as the external environment factors. Among them, laws and regulations factors are both opportunities and challenges for logistics enterprises to develop logistics finance. At the same time, due to the unpredictable market situation, the price of the pledge is not stable; logistics enterprises will bear certain risks.

Table 4 Rotated Component Matrix

\begin{tabular}{lcccc}
\hline & \multicolumn{4}{c}{ Component } \\
& 1 & 2 & 3 & 4 \\
\hline $\mathrm{X}_{1}$ & -0.086 & -0.023 & -0.091 & 0.865 \\
$\mathrm{X}_{2}$ & -0.065 & 0.043 & -0.010 & 0.891 \\
$\mathrm{X}_{3}$ & 0.868 & 0.101 & -0.069 & -0.139 \\
$\mathrm{X}_{4}$ & 0.870 & 0.064 & 0.091 & -0.084 \\
$\mathrm{X}_{5}$ & 0.864 & -0.049 & 0.034 & 0.014 \\
$\mathrm{X}_{6}$ & -0.048 & 0.832 & -0.045 & 0.086 \\
$\mathrm{X}_{7}$ & -0.175 & 0.632 & -0.278 & 0.164 \\
$\mathrm{X}_{8}$ & 0.089 & 0.710 & 0.205 & -0.295 \\
$\mathrm{X}_{9}$ & 0.241 & 0.551 & -0.040 & -0.010 \\
$\mathrm{X}_{10}$ & 0.113 & -0.107 & 0.844 & -0.165 \\
$\mathrm{X}_{11}$ & 0.084 & 0.122 & 0.788 & -0.144 \\
$\mathrm{X}_{12}$ & -0.154 & -0.138 & 0.635 & 0.186 \\
\hline
\end{tabular}

\section{Suggestions on Measures to Promote Logistics Enterprises to Develop Logistics Financial Services}

\subsection{Improving the pledge management system.}

Establish and improve the pledge management system. First, establish the evaluation index system for selecting the pledge and make reasonable selection according to various properties of the pledge. Secondly, the method of building expert team or cooperating with professional evaluation team can be adopted to improve the evaluation technology of pledges. Thirdly, supervise the pledge in real time. Determine the value of the pledge at the time of storage; guarantee the quality and quantity of the pledge 
during the storage period. Fourth, prepare for realization of the pledge. Financing enterprises are required to provide reliable channels for realization, and logistics enterprises themselves are also actively expanding the corresponding channels.

4.2 Vigorously introducing and cultivating talents and improving the level of logistics technology.

Talent is an important carrier of enterprise technology competitiveness and the cornerstone of enterprise growth and development. In the short term, logistics enterprises can temporarily take the approach of external introduction to fill the vacancy. In the long run, however, companies need to reform from within. Logistics enterprises should provide regular vocational training for their employees to improve their professional quality and reduce the corresponding operational risks. Meanwhile, excellent employees should be selected for further study to cultivate high-end talents for the enterprises. At the same time, an independent technical department was established to strengthen the introduction of advanced logistics technologies and improve the level of enterprise logistics technology.

\subsection{Building information sharing platform and establishing credit evaluation system.}

The credit risk of logistics enterprise comes from financing enterprise. Sufficient information disclosure is the best credit guarantee. First, establish an information sharing platform between industries to record the credit status of financing enterprises in the transaction process. Second, establish a sound credit evaluation system, carry out dynamic examination of the credit record, asset status, production and operation capacity of financing enterprises, and achieve accurate credit evaluation of financing enterprises.

\subsection{Promoting the improvement of relevant laws and regulations and establishing a win-win relationship with the local government.}

Logistics enterprises should carefully refer to and strictly implement the regulations on supporting or restricting the related business of logistics finance in the legal policies. According to the actual situation, put forward relevant policy demands to relevant departments, feedback the lack of laws and regulations, and then promote the improvement of laws and regulations. Based on the actual situation of the enterprise, carry out the project planning according to the government logistics development plan, take the initiative to cooperate with the local government to build effective cooperation projects, establish cooperative partnership, and achieve a win-win situation.

\section{Conclusion}

The development of logistics finance is mainly driven by third party logistics enterprises in china, which is different from developed counties that are mainly driven by financial institutions. Analyzing the factors that affecting financial services from the perspective of logistics enterprises is the key to promote the development of logistics finance. The development of the financial service of logistics enterprises is influenced by many factors. The paper concludes that the main factors influencing the financial service of logistics enterprises include pledge factors, internal factors of logistics enterprises, credit factors of related subjects and external environment factors. At the same time, corresponding measures and suggestions are put forward: improve the management system of pledges; vigorously introduce and cultivate talents, and improve the level of logistics technology; build information sharing platform and establish credit evaluation system; promote the improvement of relevant laws and regulations and establish a win-win relationship with local governments.

\section{References}

[1]. ZOU Xiao-peng, and TANG Yuan-qi, “Analysis of logistics finance,” Zhejiang finance, pp. 20-21, May 2004. (In Chinese)

[2]. LI Yi-xue, WANG Shou-yang, and FENG Geng-zhong, “A new subject direction: the practical development and theoretical review of logistics finance," System engineering theory and practice, vol. 30, pp. 1-13, Jan. 2010. (In Chinese) 
[3]. LI Yi-xue, "Analysis of logistics financial risk identification based on financial system engineering," East China economic management, vol. 25, pp. 35-39, Oct. 2011. (In Chinese)

[4]. SUN Tong-chao, and ZHAO Su-xia, "On the development status of logistics finance in China," Journal of chongqing jiaotong university (social science edition), vol. 7, pp. 18-21, Dec. 2007. (In Chinese)

[5]. WANG Yan, "Research on the measurement of logistics financial risk from the perspective of commercial Banks,” Commercial economic research, pp. 83-84, Sept. 2015. (In Chinese)

[6]. HE Ming-ke, QIAN Wen-bin, “Logistics financial risk management process,” Systems engineering, vol. 28, pp. 30-35, May 2010. (In Chinese) 